\title{
Average Fuel Consumption Calculation Model of Touring Coach Based on OBD Data- A Case Study in City $X$
}

\author{
Xiaolin Che ${ }^{1, a}$, Quan Yu ${ }^{1, b}$, Guangli Ren ${ }^{1, c}$ and Rui Liang ${ }^{1, d}$ \\ ${ }^{1}$ Beijing Engineering Research Center of Urban Transport Operation Guarantee, Beijing University \\ of Technology, No.100 of Pingleyuan Region, Chaoyang District, Beijing, CN100124, China

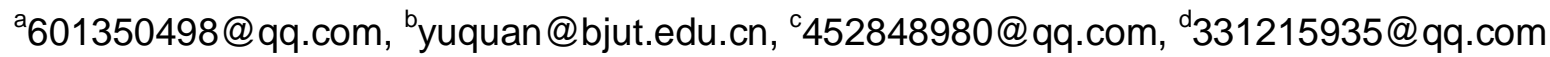

\begin{abstract}
Keywords: Fuel consumption; Road type; Touring coach
Abstract. Reducing fossil fuel consumption of transportation is one of the key for energy conservation and emission reduction of every megacity. The essential data of this research came from 4 similar kinds of touring coaches including 64 vehicle trips whose cumulative operating time and mileage were 778.8 hours and 17,816 kilometers. In this research, the average fuel consumptions in different road types were figured out based on the fuel consumption calculation model. This was a case study of registered touring coaches in city $\mathrm{X}$, the R-Squared of the regression equation of speed and instantaneous fuel consumption was 0.993 . The accuracy of model measured from following test of other 3 vehicle trips was $91.69 \%$. The average fuel consumption calculation model was built as theoretical foundation for optimizing vehicle distribution of passenger transportation market.
\end{abstract}

\section{Introduction}

The fuel consumption of vehicles in developing countries contributed a lot and increased daily[1]. Based on the summarization of present literatures, the changing form of fuel consumption of different vehicle were distinct[2]. The fuel consumption was strongly correlated with properties of vehicle, such as rated passenger capacity, engine power, travelled mileage, transmissions, tyre vibration, auxiliary equipment, brakes, and so on[3]. To get the high accuracy changing rule between fuel consumption and speed, four kinds of different brand touring coaches which were similar in shape, engine power, rated passenger capacity, travelled mileage and vehicle weight were collected. Fuel consumption was also related to pavement type[4,5], so this research focused on six types of road: freeway, express way, main road, minor road, branch road, side road, which pavement type were all asphalt (AC). Because the fuel consumption of low speed is strongly related to many other factors which were not the objectives of this research and would significantly increase[6], data with speed value higher than $16 \mathrm{~km} / \mathrm{h}$ and lower than design speed were specially collected. And the average fuel consumption calculation model was built by regression analysis and the accuracy of model reached $91.69 \%$. At last, the expected values of fuel consumption in six road types were worked out.

\section{Fuel Consumption Data Collection}

To some other factors which were not in the scope of this research, the registered touring coaches of city $\mathrm{X}$ in similar shape, engine power, rated passenger capacity, travelled mileage and vehicle weight but different in brand were selected. The details were shown in Table 1. As the complicated statistic process of calculating cumulative operating mileage from producing and the average operating mileage per day of each touring coach in city $\mathrm{X}$ were approximate, the travelled mileage parameter was replacing with registration date. Zhang[6] worked out the fuel consumptions of all kinds types of transport buses with portable emission measurement systems in Beijing. In his research, although road type was considered, the R-Squared of the model he built in which the speed of test buses were all below $60 \mathrm{~km} / \mathrm{h}$ was just about 0.68 .

In this research, most of test touring coaches could reach the design speed of all kinds of road types in durations. 
Table1. List of Vehicle Parameters

\begin{tabular}{cccccc}
\hline $\begin{array}{c}\text { Vehicle } \\
\text { Brand }\end{array}$ & $\begin{array}{c}\text { Shape } \\
\text { [Enclosed/ } \\
\text { Half-Open] }\end{array}$ & $\begin{array}{c}\text { Engine } \\
\text { Power } \\
{[\mathrm{kw}]}\end{array}$ & $\begin{array}{c}\text { Rated Passenger } \\
\text { Capacity } \\
{[\text { person] }}\end{array}$ & $\begin{array}{c}\text { *Registration } \\
\text { Date } \\
{[\text { MM.YYYY] }}\end{array}$ & $\begin{array}{c}\text { Vehicle } \\
\text { Weight } \\
{[\mathrm{kg}]}\end{array}$ \\
\hline A & Enclosed & 240 & 50 & 06.2008 & 12900 \\
B & Enclosed & 240 & 50 & 06.2008 & 12900 \\
C & Enclosed & 240 & 50 & 08.2008 & 12900 \\
D & Enclosed & 240 & 50 & 08.2008 & 12900 \\
\hline
\end{tabular}

The fields of On-Board Diagnostic(OBD) data involved vehicle basic information, track information and hourly fuel consumption information, which including recording time, license plate number, longitude, latitude, dashboard speed, instant hourly fuel consumption and road type. 4,700,000 of OBD data of 64 vehicle trips accumulating 778.8 hours was collected, the average interval of recording time were 6 seconds. The research scope of speed of six road types should be limited to avoid the influence of PnG (pulse-and-gliding which was an effective way of saving fuel by speeding up in a short time and then gliding to low speed) [7]. PnG could happen in every road type when space headway was long enough.

\section{Fuel Consumption Calculation Models of Six Road Types}

The fuel consumption of 64 vehicle trips for every recording time interval came from instant fuel consumption and dashboard speed. The operating line of every vehicle trips were classified as freeway, express way, main road, minor road, branch road, side road. The statistical fuel consumption for every speed was the median of all instantaneous fuel consumptions. The R-Squared results of regression analysis between speed and instantaneous fuel consumption of six road types were all high than 0.98 as Fig.1 showed. So the six fitted equations had statistical significance.
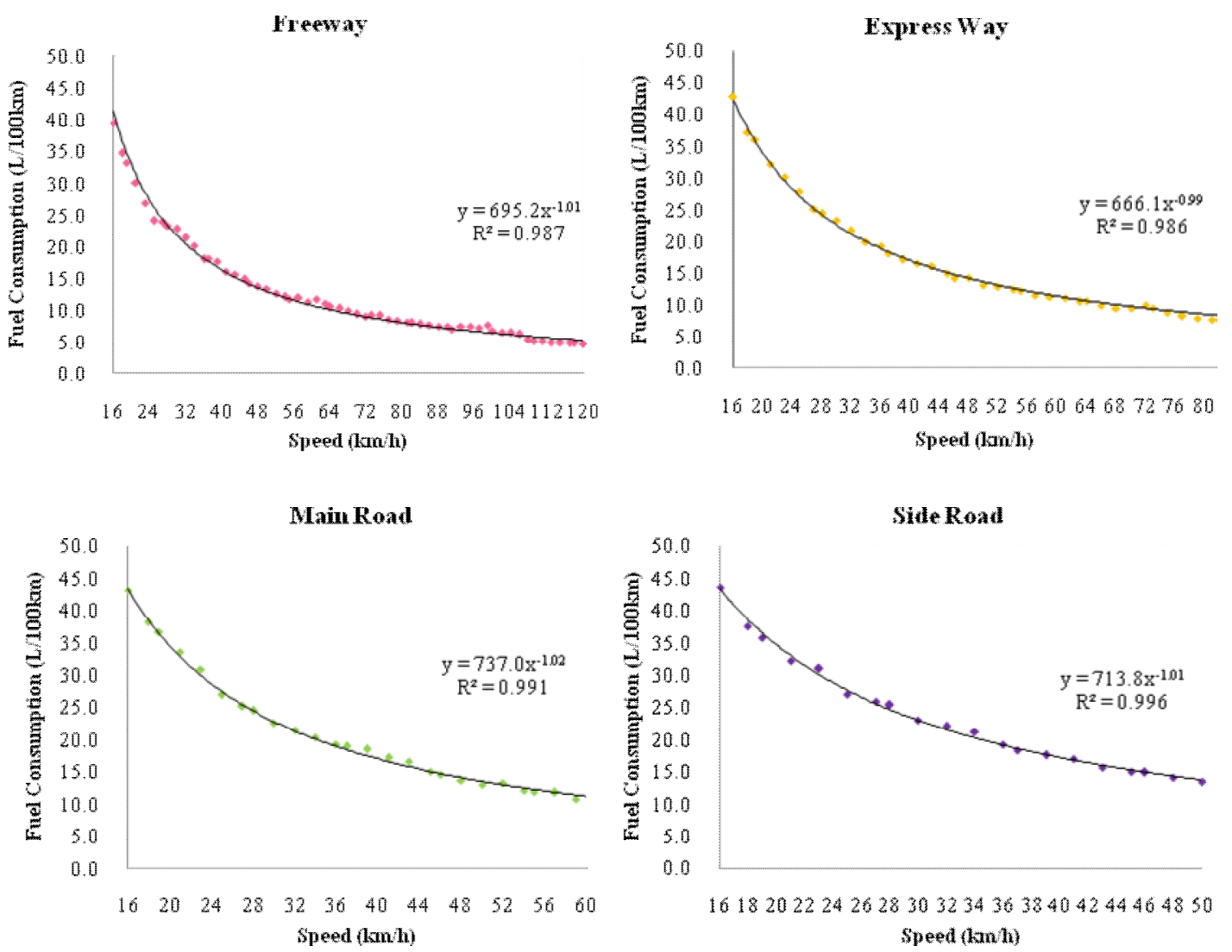

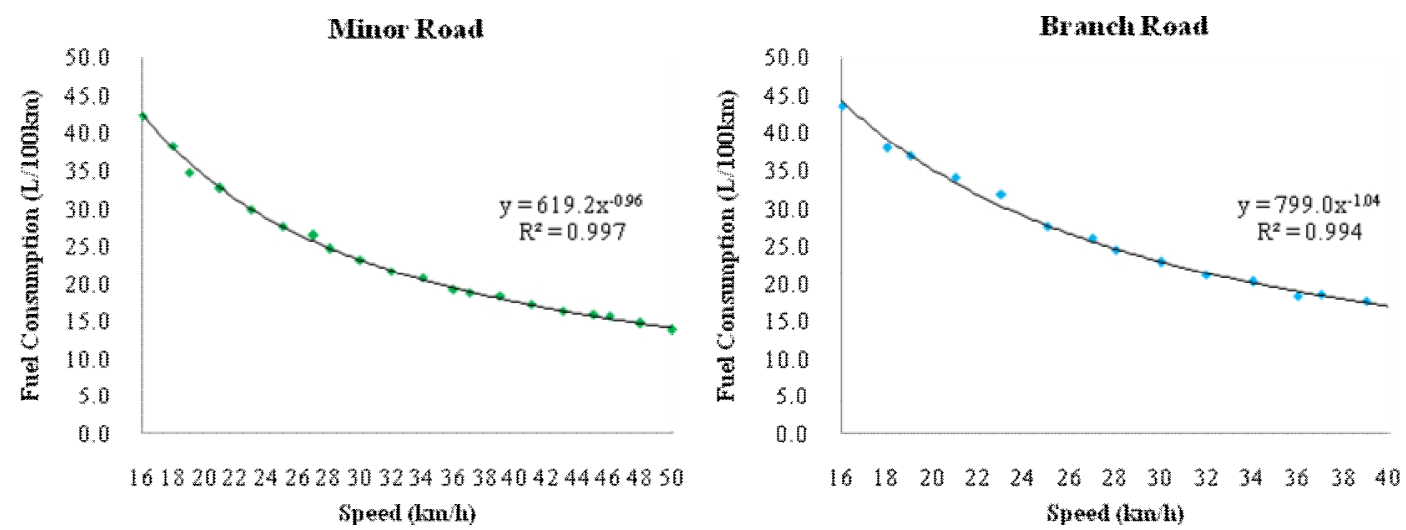

Fig.1. Correlation between Fuel Consumption and Speed for Six Road Types

According to the statistical results, the consumption of statistic fuel was from high to low. And that distribution rule had a significant influence on expected values of fuel consumption of six road types. The valid OBD data with information of operating line and fuel consumption were selected by deleting faulty data. Speed appearing rate was the percentage of the appearing times of a speed account for the quantity of recording time in whole operating time. As Fig. 2 showed, the speed appearing rate restricted the average speed of six road types, which straightly reflecting the influence of driving speed from road types. The driving speed increases as the level of road type increased.

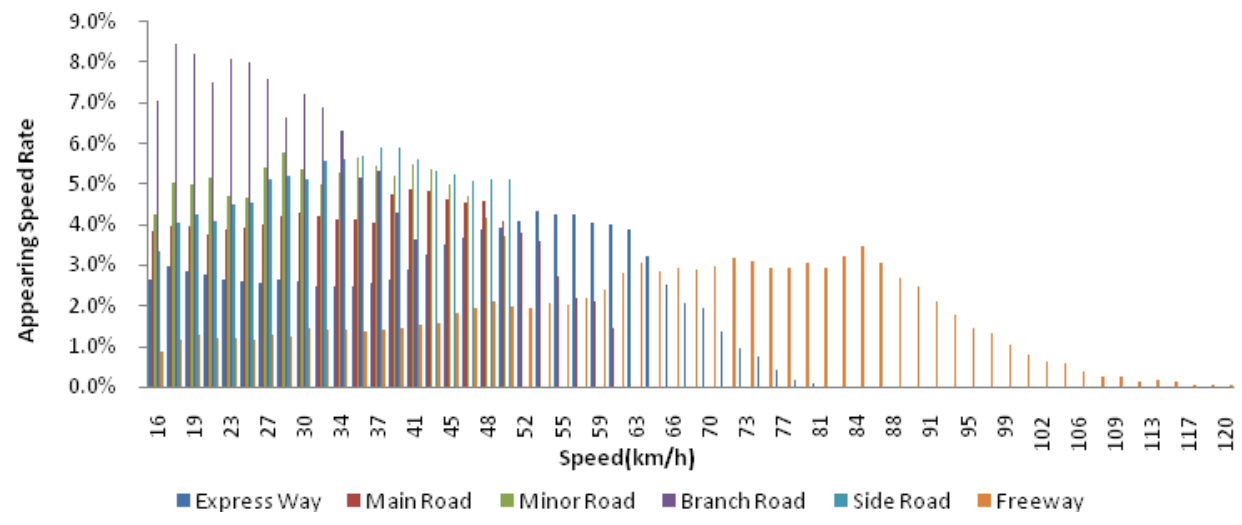

Fig.2. Speed Appearing Rate for Six Road Types

\section{Average Fuel Consumption Calculation Model}

Average fuel consumption calculation model came from the six fuel consumption calculation models of six road types. The regularity of six fuel consumption calculation models of different road types was outstanding. The fuel consumption calculation model of city $\mathrm{X}$ is based on the six models. As was shown in Equation 1, the R-Squared of the fitted equation based on regression analysis of statistic fuel consumption of six road types was 0.993. So the fitted equation had statistical significance.

$$
f_{c}=778.5 v^{-1.03}
$$

where $f_{c}$ is average fuel consumption, $\mathrm{L} / 100 \mathrm{~km} ; v$ is driving speed, $\mathrm{km} / \mathrm{h}$.

As Fig. 3 showed, the variation regularity of speed and average fuel consumption followed power function distribution which declined rapidly before kept steady. The average fuel consumption of touring coaches in city X remained $7 \mathrm{~L} / 100 \mathrm{~km}$ stably while speed reached $80 \mathrm{~km} / \mathrm{h}$. 
As the result, the fuel consumption of these touring coaches driving on freeway would be much lesser than on low-level road types.

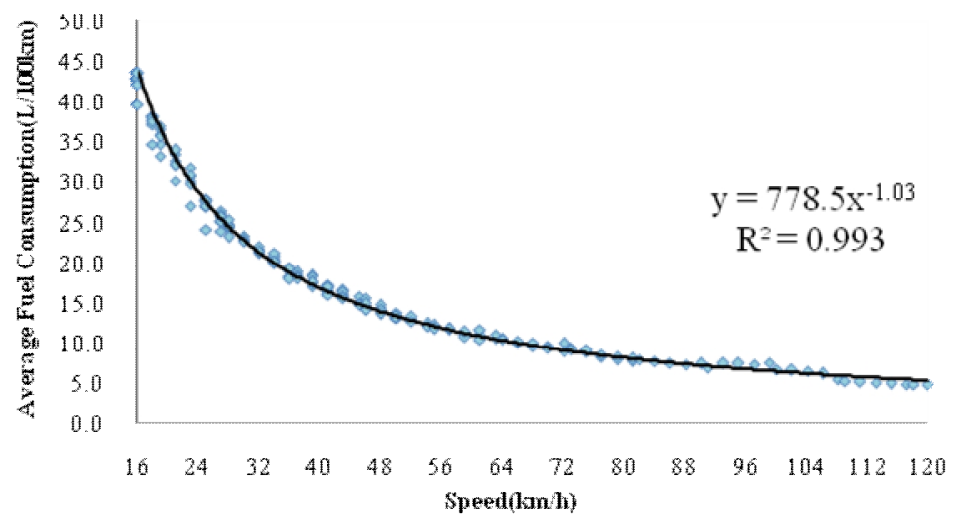

Fig.3 Correlation between Average Fuel Consumption and Speed

The new 3 vehicle trips operating data which selected from other touring coaches which was in the same type with above four kinds of touring coaches were used to verify the model accuracy. At first, the operating data were filtered in above three steps. The results of five groups T-test which were taken between every group of real fuel consumption and statistical fuel consumption reflected they were strongly related, as Table 2 showed. And the average accuracy of the model was $91.69 \%$. So the average fuel consumption calculation model had statistical significance.

Table2. Results of Paired Samples Correlations

\begin{tabular}{lccccccc}
\hline & & & & \multicolumn{4}{c}{ Bootstrap for Correlationa } \\
& $\mathrm{N}$ & Correlation & Sig. & Bias & Std. Error & $\begin{array}{c}\text { 95\% Confidence Interval } \\
\text { Lower }\end{array}$ & Upper \\
\hline Pair 1 & 59 & .998 & .000 & .000 & .001 & .997 & .999 \\
Pair 2 & 44 & .989 & .000 & -.001 & .005 & .976 & .995 \\
Pair 3 & 42 & .958 & .000 & .001 & .015 & .928 & .982 \\
\hline
\end{tabular}

And then, the expected fuel consumptions for six road types were calculated on the average fuel consumptions and the speed appearing rate for six road types. As Fig.4 showed, the fuel consumption of freeway, express way, main road, minor road, side road and branch road respectively were $13.1 \mathrm{~L} / 100 \mathrm{~km}, 18.3 \mathrm{~L} / 100 \mathrm{~km}, 21.8 \mathrm{~L} / 100 \mathrm{~km}, 24.0 \mathrm{~L} / 100 \mathrm{~km}, 23.0 \mathrm{~L} / 100 \mathrm{~km}$ and $28.3 \mathrm{~L} / 100 \mathrm{~km}$. The result of the six expected fuel consumptions were clustered in three levels: excessive level, saving and normal levels. For city $\mathrm{X}$, the touring coaches driving on free way belonged to saving level; driving on express way, main road, minor road and side road belonged to normal level; driving on branch road belonged to excessive level. Obviously, this type of touring coaches in city $\mathrm{X}$ was more suitable for long-distance passenger transportation than serving short-distance trip. 


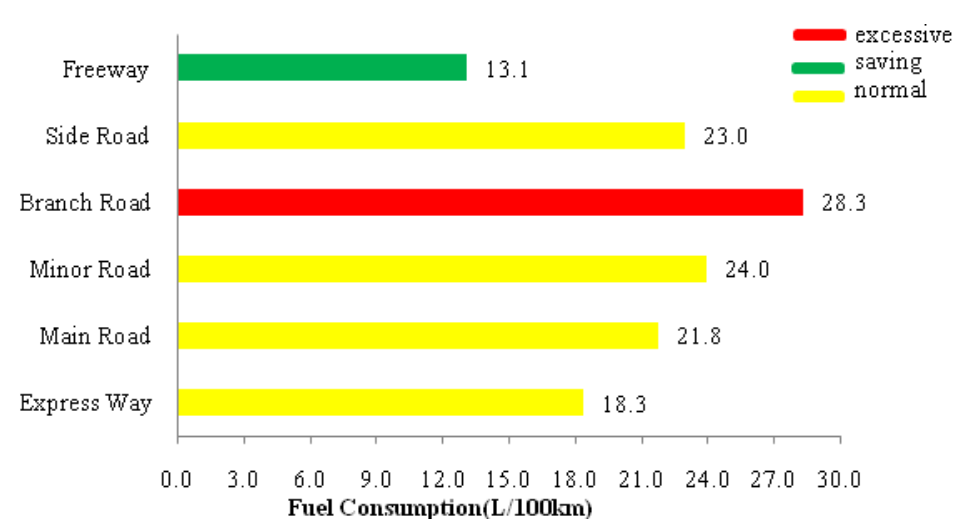

Fig.4 Expected Fuel Consumption for Six Road Types

\section{Conclusions}

The rules for filtering 64 registered touring coaches' data were built to analyze the variation regularity of speed and fuel consumption. The fuel consumption calculation models of freeway, express way, main road, minor road, branch road and side road which R-Squared results were all high than 0.98 were built on scientific analysis. The average fuel consumption calculation model of touring coaches in city X which R-Squared result was 0.996 and accuracy reached $91.69 \%$ was built on the correlation between fuel consumption and speed for six road types. Finally, the expected fuel consumptions of six road types were reached by calculating on average fuel consumption calculation model and speed appearing rate. In conclusion, this kind of touring coaches was more suitable for long-distance passenger transportation.

\section{References}

[1] Borken, Jens; Steller, Heike; Merétei, Tamás; Vanhove, Filip; "Global and country inventory of road passenger and freight transportation: Fuel consumption and emissions of air pollutants in year 2000”; Transportation Research Record; n2011, p127-136.(2007)

[2] Ranjan Kumar Bose; "Energy demand and environmental implications in urban transport Case of Delhi", Atmospheric Environment; Volume 30, Issue 3, February(1996), Pages 403-412, ISSN 1352-2310.

[3] Hong Wang; "Bus/Coach Powertrain Matching Based on Fuel Consumption Simulation"; Bus Technology and Research; 04:8-10.(2013)

[4] Zaabar, Imen; Chatti, Karim. "A field investigation of the effect of pavement type on fuel consumption"; T and DI Congress 2011: Integrated Transportation and Development for a Better Tomorrow - Proceedings of the 1st Congress of the Transportation and Development Institute of ASCE, p 772-781.(2011)

[5] Darr, Linda, Buchanan, Brandon, Jack, Jason, Lowell, Dana, Shires, Christopher; "Commercial Bus Emissions and Fuel Use: Idling Versus Urban Circulator. Transportation Research Record"; Transportation Research Board; pp 57-67.(2011)

[6] Shaojun Zhang; Ye Wu; Huan Liu; Ruikun Huang; Puikei Un; Yu Zhou; Lixin Fu; Jiming Hao; "Real-world fuel consumption and $\mathrm{CO} 2$ (carbon dioxide) emissions by driving conditions for light-duty passenger vehicles in China"; Energy, v 69, p 247-257, May 1.(2014)

[7] Li, S Eben; Peng, H; "Strategies to minimize the fuel consumption of passenger cars during car-following scenarios Source: Proceedings of the Institution of Mechanical Engineers"; Automobile Engineering; v 226, n 3, p 419-429, March.(2012) 